\title{
Systematic Review on the Robotic and Minimally Surgery in the Treatment of the Prostate
}

\author{
Dr. Idiberto Jose Zotarelli Filho, MSc, Ph.D ${ }^{1}$ \\ ${ }^{1}$ Affiliation not available
}

June 4, 2020

\begin{abstract}
Introduction: In the context of robotic surgery (RS), approximately 1.5 million robotic surgeries have been performed worldwide in the past decade. In Brazil, prostate cancer is the second most common among men (behind only non-melanoma skin cancer). In absolute values and considering both sexes, it is the fourth most common type and the second most incident among men. Objective: Therefore, the present study aimed to present, through a systematic review, the main approaches to RS as a minimally invasive procedure for the prostate. Methods: After literary search criteria with the use of Mesh terms were used the main databases such as Pubmed, Medline, Bireme, EBSCO, Scielo, etc., a total of 55 papers that were submitted to the eligibility analysis were cross-checked and after that 20 studies were selected, following the rules of systematic reviewPRISMA. Results and Conclusion: The scientific evidence reported points to some potential benefits of robotically assisted surgery compared to open surgery and laparoscopic surgery. The outcomes related to less blood loss and consequently less need for blood transfusion, as well as the preservation of sexual function seem to be the most significant advantages in relation to comparators. Better urinary continence and shorter hospital stay due to lower rates of perioperative complications are also reported in the studies.
\end{abstract}

Keywords: Robotic surgery. Minimally invasive surgery. Prostate cancer. Prostatectomy.

\section{José Fernando Coelho ${ }^{1,2}$, Anésia Sodré Coelho², Idiberto José Zotarelli Filho ${ }^{3,4}$}

${ }^{1}$ UNISA-University of Santo Amaro / FMSA- Faculty of Medicine of Santo Amaro, Santo Amaro/SP, Brazil.

${ }^{2}$ Sodré Coelho Training and Consulting Center/ FCE-Campos Elíseos Faculty, São José do Rio Preto/SP, Brazil.

${ }^{3}$ Zotarelli-Filho Scientific Work, São José do Rio Preto, SP, Brazil.

${ }^{4}$ Bentham Science Ambassador, Brazil.

Corresponding Author: Dr. Idiberto José Zotarelli Filho, MSc, Ph.D, Zotarelli-Filho Scientific Work, São José do Rio Preto, SP, Brazil. Tel: +55(17) 98166-6537; email: m.zotarelli@gmail.com

\section{Introduction}

In the context of robotic surgery (RS), about 1.5 million robotic surgeries have been performed worldwide in the past decade or that $83 \%$ of prostatectomies were performed robotically in 2011, compared with only $17 \%$ just 6 years before (Intuitive Surgical, 2015) [1]. In the years after 2007, the number of procedures assisted by robotics almost tripled worldwide from 80,000 to more than 200,000 . The number of da Vinci 
robotic surgical consoles grew $75 \%$ between 2007 and 2009 (from 800 to 1,400 in the USA and from 200 to 400 abroad) $[1,2]$.

RS has been widely adopted in several specialties and in urology, it is used for reconstructive, pediatric, urogynecological and obviously oncological procedures. In 2014, the total volume of procedures in the USA was 449,000, of which $20 \%$ in urology, $52 \%$ in gynecology and $24 \%$ in general surgery. The volume of international procedures was 1121,000 in 2014, of which most procedures were in urology [1].

In this scenario, the prostate is a gland that is located in the lower part of the abdomen. It is a small organ located just below the bladder and in front of the rectum that surrounds the initial portion of the urethra [3]. In Brazil, prostate cancer is the second most common among men (behind only non-melanoma skin cancer). In absolute values and considering both sexes, it is the fourth most common type and the second most incident among men. The incidence rate is higher in developed countries compared to developing countries [3]. More than any other type, it is considered a cancer of the third age, since about three-quarters of the cases in the world occur from the age of 65 [4].

The increase observed in incidence rates in Brazil can be partially justified by the evolution of diagnostic methods, by the improvement in the quality of the country's information systems and by the increase in life expectancy. Some of these tumors can grow quickly, spread to other organs and can lead to death. The vast majority, however, grows so slowly (about 15 years to reach $1 \mathrm{~cm}^{3}$ ) that it does not show signs during life or threaten the health of man [5]. According to INCA - National Cancer Institute, the estimate of new cases for the year 2016 was 61,200 cases and the number of deaths determined in the year 2013 was 13,772 deaths. The risk of a man having a prostate cancer diagnosed during his life is $16 \%$, as it demonstrates the prevalence of this neoplasm, however, the risk of death from prostate cancer is only $3.4 \%$, which reaffirms his indolence in a large proportion of cases [5].

Therefore, this study aimed to present, through a systematic review, the main approaches to robotic surgery as a minimally invasive procedure for the prostate.

\section{Methods}

\section{Study design}

Following the criteria of literary search with the use of the Mesh Terms that were cited in the item below on "Search strategies", a total of 55 papers that were submitted to the eligibility analysis were collated and, after that, 20 studies were selected, following the rules of systematic review-PRISMA (Transparent reporting of systematic reviews and meta-analyzes-http: //www.prisma-statement.org/).

\section{Search strategy and sources of information}

In general, the search strategy in MEDLINE / Pubmed, Web of Science, ScienceDirect Journals (Elsevier), Scopus (Elsevier), OneFile (Gale) followed the following steps: - search for MeSH Terms: Robotic surgery. Minimally invasive surgery. Prostate cancer. Prostatectomy and use of the bouleanos "and" between the mesh terms and "or" among the historical findings.

\section{Flow Chart}




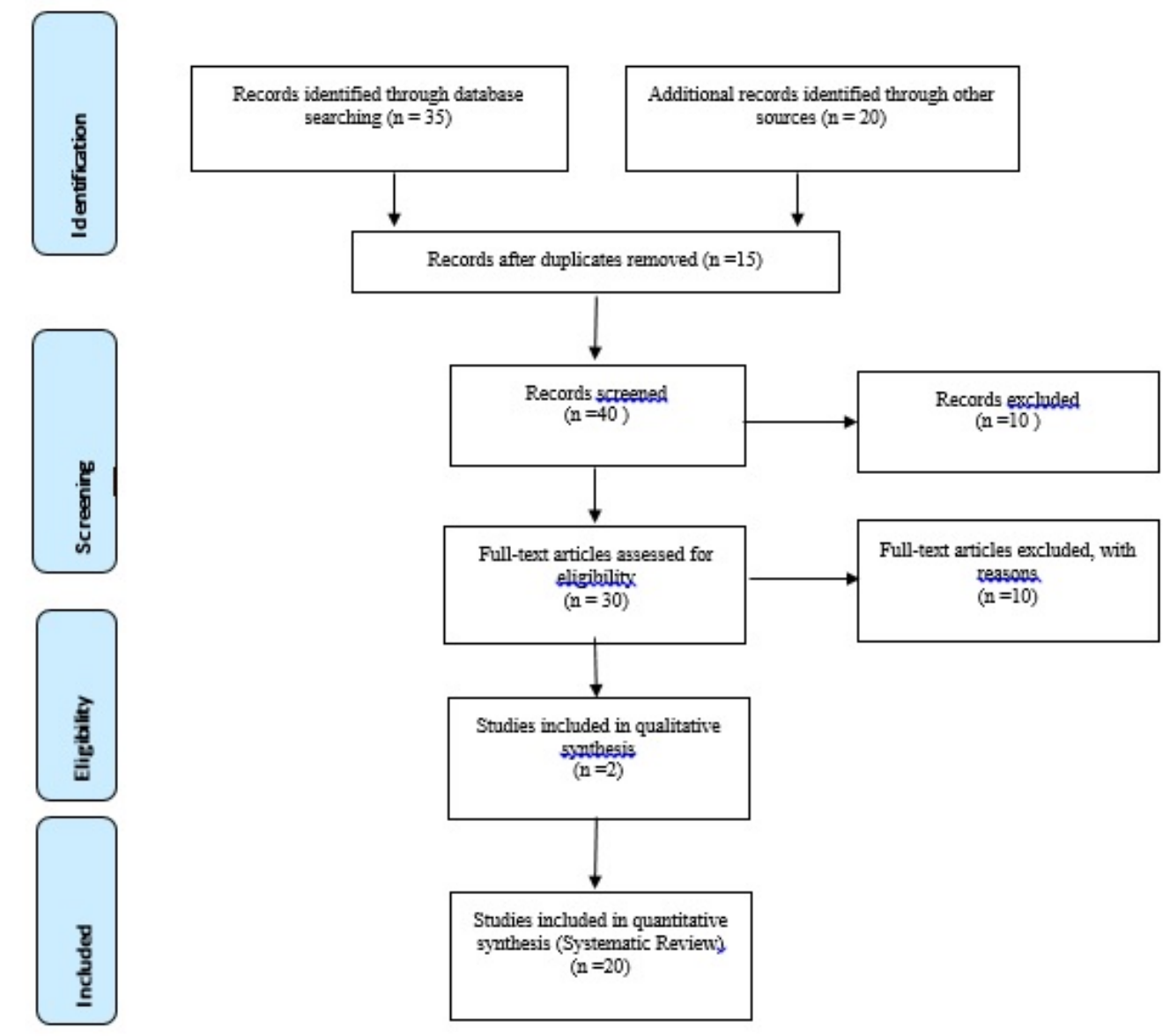

\section{Literature Review and Discussion}

Robotics-assisted surgery has spread rapidly as a technique to develop laparoscopic surgery through innovative technological improvements, such as 3D imaging with a high magnifying lens and freedom of clamps in varying degrees, leading to improved safety and better functional recovery. In the urological field, it enabled a highly fine operation in a narrow field, such as the pelvic cavity or retroperitoneal space. Better results were recognized especially in perioperative complications and recovery of postoperative QOL than other procedures such as open or laparoscopic. Robotic assistance definitely brought a paradigm shift in urological surgery $[6]$.

In this sense, a study presented simple transvesical prostatectomy via percutaneous single door using the new robotic surgical system SP (B. Ten patients underwent simple single-door transvesical prostatectomy between February and November 2019. Percutaneous access to the bladder dome was performed and all SP

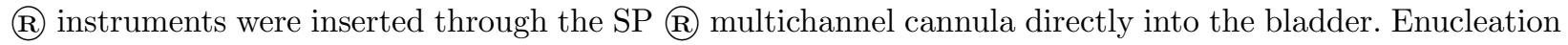
of the prostate adenoma, hemostasis and trigonization were performed according to the principles of the simple open prostatectomy technique. All procedures were performed successfully, without the need for conversion to open surgery. The estimated average size of the prostate in the preoperative period was 159 (IQR 108-223) grams. There were no intraoperative complications. The mean operative time and estimated blood loss were 190 (IQR 146-203) minutes and 100 (IQR 68-175) ml, respectively. The average weight of the sample in the postoperative period was $84.3 \pm 34$ grams. The average hospital stay was 19 (IQR 17 28 ) hours. All patients were satisfied with the urine flow after removal of the catheter without any episode of acute urinary retention from 1 to 6 months postoperatively. Therefore, simple single-port transvesical 
prostatectomy can be offered as an alternative treatment option for the surgical treatment of lower urinary tract symptoms associated with large prostate adenoma. Saving the peritoneal cavity, minimal bladder dissection, excellent visualization of the prostate fossa can be some of the potential advantages of this minimally invasive approach. Comparative studies with standard techniques are recommended to assess the surgical outcome and postoperative morbidity of each treatment modality [7].

Still, most of the evidence found in the present study was observational studies related to case series or case reports of several services that used the technology. Some of these studies explored only variations of the consolidated surgical techniques. The most robust studies found were 3 systematic reviews included.

The Cochrane review was designed with the aim of comparing radical prostatectomy by laparoscopy or robot-assisted radical prostatectomy with open radical prostatectomy, in men with localized prostate cancer. Searches were carried out in multiple databases for randomized clinical trials (RCTs), or quasi-randomized, published until June 2017, for direct comparison between technologies. Study selection, data extraction, and quality assessment were performed by 2 independent researchers. Only 2 RCTs were included, one comparing laparoscopic prostatectomy with open surgery [18] and the other comparing robot-assisted prostatectomy with open surgery [19] in participants with localized prostate cancer. In this report, only the results of the study that evaluated robot-assisted prostatectomy will be considered [19]. The outcomes of overall survival and prostate cancer-related survival have not been evaluated.

In addition, another study showed that there were no differences between robot-assisted prostatectomy and open prostatectomy for quality of life, urinary and sexual outcomes, surgery-related complications, severe complications and pain after 12 weeks of surgery. Robot surgery has reduced hospital stay compared to open surgery [17].

The duration of surgery (mean of 202.03 minutes (standard deviation SD $=51.36$ ) versus 234.34 minutes $(\mathrm{SD}=37.07) ; \mathrm{p}<0.001$ and time in the operating room (mean of 246,08 minutes $(\mathrm{SD}=55.12)$ versus 280.37 minutes $(\mathrm{SD}=36.36) ; \mathrm{p}<0.0001$ were lower for robot-assisted prostatectomy than for open prostatectomy, respectively, however, there was no difference between the groups in time spent on recovery. [19] The estimate of total blood loss was lower for robot-assisted prostatectomy than for open prostatectomy (443.74 $\mathrm{mL}$ (SD $=294.29)$ versus $1,338.14 \mathrm{~mL}(\mathrm{SD}=591.47) ; \mathrm{p}<0.0001[19]$.

In addition, the systematic review with meta-analysis prepared by the Austrian institute Ludwig Boltzmann Institut für Health Technology Assessment (LBI-HTA) 9 in 2015 assessed the effectiveness, safety, and costs associated with the use of RS in some selected indications. For the radical prostatectomy procedure, the comparators selected were open surgery and laparoscopic surgery. None of the studies identified showed an explicit benefit of RS for patients, including nephrectomy, adrenalectomy, prostatectomy, cystectomy or hysterectomy procedures. Specifically for the outcomes related to the prostatectomy procedure, 1 randomized clinical study and 8 prospective cohort studies were included. The main results of meta-analysis on robotically assisted radical prostatectomy included in the systematic review for outcomes: urinary continence 6 and 12 months after surgery, sexual dysfunction, duration of the surgical procedure and general complications [20]. The meta-analysis showed no statistically significant difference between robot-assisted surgery and open surgery in the patient's likelihood of continence 6 or 12 months after surgery. In addition, there was a relatively high heterogeneity ( $\mathrm{I}^{2}=66$ and $72 \%$, respectively) between studies [20].

The meta-analysis showed that robot-assisted surgery was more likely to maintain sexual function preserved 12 months after surgery than with open surgery (relative risk 1.59; 95\% CI 1.28 to 1.99). Although with relatively high heterogeneity $\left(\mathrm{I}^{2}=73 \%\right)$, all studies showed an effect in favor of RS. The meta-analysis showed a shorter stay of 1.5 days in a robot-assisted prostatectomy compared to open surgery $(\mathrm{p}<0.0001)$. The studies, however, showed a very high heterogeneity $\left(\mathrm{I}^{2}=99 \%\right)[20]$.

The meta-analysis showed a difference in the occurrence of general complications between a robot-assisted prostatectomy and an open surgical prostatectomy, statistically significant $(\mathrm{p}=0.05)$ in favor of robotassisted prostatectomy (relative risk 0.72). However, individual studies showed a high heterogeneity $\left(\mathrm{I}^{2}=\right.$ $72 \%$ ), with favorable effects on both sides, both in favor of the intervention and for the comparator [20]. 
Assessment of the quality of evidence and risk of bias Regarding the comparison of robotically assisted surgery with open surgery or surgery via laparoscopy, the systematic review, in general, showed a low risk of bias, having clearly defined the structured question, the literature search, independent evaluations, heterogeneity analysis, and statistical analysis. The identified cohort studies, both in comparison with open surgery and laparoscopic surgery, demonstrated a high risk of selection bias and the description of a similar prognosis was not described in detail. In addition, the high heterogeneity, the low number of patients, the lack of blinding and the lack of a report on the loss of patients who are no longer part of the studies also contributed to the quality of the evidence being lowered. The quality of these studies and the strength of the evidence were considered low. Specifically, in comparison with laparoscopic surgery, the risk of bias from the included RCT was considered low, with only a high risk detected for a performance bias caused by the absence of blinding. Only in outcomes where the RCT can be taken into account, the level of evidence can be considered moderate. The risk of bias present in the studies is represented in figures 17 to 20 and the level of quality of the evidence demonstrated in tables 3 and 4 using the GRADE tool (Grading of Recommendations Assessment, Development, and Evaluation) [20].

\section{Conclusion}

The scientific evidence reported points to some potential benefits of robotically assisted surgery compared to open surgery and laparoscopic surgery. The outcomes related to less blood loss and consequently less need for blood transfusion, as well as the preservation of sexual function seem to be the most significant advantages in relation to comparators. Better urinary continence and shorter hospital stay due to lower rates of perioperative complications are also reported in the studies.

\section{Declaration of Potential Conflict of Interest}

The authors declare no conflict of interest.

\section{Funding}

We would like to thank financial support of Sodré Coelho Training and Consulting Center/ FCE-Campos Elíseos Faculty, São José do Rio Preto/SP, Brazil.

\section{References}

1. Carpenter BT, Sundaram CP. Training the next generation of surgeons in robotic surgery. Robot Surg. 2017 Apr 21;4:39-44. doi: 10.2147/RSRR.S70552. eCollection 2017.

2. Ahmed K, Abboudi H, Guru KA, Khan MS, Dasgupta P. Robotic surgical technology is here to stay and evolve. Trends Urol Men's Health. 2013;4:32-36.

3. Brasil, Ministério da Saúde, Secretaria de Atenção à Saúde, Instituto Nacional de Câncer José Alencar Gomes da Silva, Coordenação Geral de Ações Estratégicas, Coordenação de Prevenção e Vigilância. Câncer de Próstata, Estimativas e Tratamento. Rio de Janeiro: INCA; 2017. Disponível em: http://www2.inca.gov.br/wps/wcm/connect/tiposdecancer/site/home/prostata.

4. Brasil, Ministério da Saúde, Secretaria de Atenção à Saúde. Diretrizes Diagnósticas e Terapêuticas do Adenocarcinoma de Próstata. Brasília: 2016. Disponível em: http://conitec.gov.br/images/Protocolos/DDT/DDT_Adenocarcinoma_Prostata.pdf

5. Brasil, Ministério da Saúde, Secretaria de Atenção à Saúde, Instituto Nacional de Câncer José Alencar Gomes da Silva, Coordenação Geral de Ações Estratégicas, Coordenação de Prevenção e Vigilância. Cartilha sobre Câncer de Próstata, Vamos falar sobre isso? Rio de Janeiro: INCA; 2017. Disponível em: http://www1.inca.gov.br/inca/Arquivos/comunicacao/cartilha_cancer_prostata_2017_final_WEB.pdf

6. Shiroki R, Fukami N, Fukaya K, Takahara K, Kusaka M. Robotic Surgery for Urologic Malignancy - Prostate, Kidney and Bladder. Gan To Kagaku Ryoho. 2018 Dec;45(12):1706-1709.

7. Kaouk J, Sawczyn G, Wilson C, Aminsharifi A, Fareed K, Garisto J, Lenfant L. Single-Port Percuta-

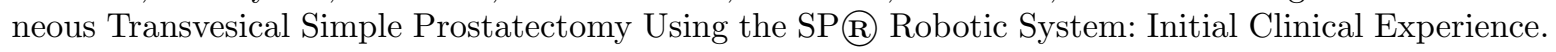
Urology. 2020 Mar 11. pii: S0090-4295(20)30261-2. doi: 10.1016/j.urology.2020.02.024. 
8. Kaouk J, Bertolo R, Eltemamy M, Garisto J. Single-Port Robot-Assisted Radical Prostatectomy: First Clinical Experience Using The SP Surgical System. Urology.2019 Feb;124:309. doi: 10.1016/j.urology.2018.10.025.

9. Kaouk JH, Sagalovich D, Garisto J. Robot-assisted transvesical partial prostatectomy using a purposebuilt single-port robotic system. BJU Int 2018 Sep; 122(3):520-524.

10. Cooper MA, Ibrahim A, Lyu H, Makary MA. Underreporting of robotic surgery complications. J Healthc Qual. 2015;37:133-138.

11. Aghazadeh MA, Jayaratna IS, Hung AJ, et al. External validation of Global Evaluative Assessment of Robotic Skills (GEARS) Surg Endosc. 2015;29:3261-3266.

12. Smith R, Patel V, Satava R. Fundamentals of robotic surgery: a course of basic robotic surgery skills based upon a 14-society consensus template of outcomes measures and curriculum development. Int J Med Robot. 2014;10(3):379-384.

13. Garisto JD. Bertolo R, Kaouk J. Techinque for Docking and Port Placement Using a Purpose-built Robotic System in Human Cadaver.Urology. 2018. Sept; 119:91-96.

14. Chavali JS, Garisto J, Bertolo R, Agudelo J, Kaouk JH. Surgical Hints for Robot-assisted Transvesical Simple Prostatectomy. Urology 2018 Dec;122:185.

15. McVary KT, Dahm P, Kohler TS, Lerner LB, Parsons JK, Wilt TJ, Foster HE. Surgical Management of Lower Urinary Tract Symptoms Attributed to Benign Prostatic Hyperplasia: AUA Guideline Amendment 2019. J Urol. 2019 Sep, 202(3): 592-598. doi: 10.1097/JU.0000000000000319.

16. Sorokin I, Sundaram V, Singla N, Walker J, Margulis V, Roehrborn C, Gahan JC. RobotAssisted Versus Open Simple Prostatectomy for Benign Prostatic Hyperplasia in Large Glands: A Propensity Score-Matched Comparison of Perioperative and Short-Term Outcomes. J Endourol. 2017;31(11):11641169.

17. Ilic D, Evans SM, Allan CA, Jung JH, Murphy D, Frydenberg M. Laparoscopic and robotic-assisted versus open radical prostatectomy for the treatment of localised prostate cancer. Cochrane Database of Systematic Reviews 2017, Issue 9. Art. No.: CD009625. DOI: 10.1002/14651858.CD009625.pub2.

18. Guazzoni G, Cestari A, Naspro R, Riva M, Centemero A, Zanoni M, et al. Intra- and perioperative outcomes comparing radical retropubic and laparoscopic radical prostatectomy: results from a prospective, randomised, single-surgeon study. European Urology 2006;50:50:98-104.

19. Yaxley J, Coughlin D, Chambers K, Occhipinti S, Samaratunga H, Zajdlewicz L, et al. Robotassisted laparoscopic prostatectomy versus open radical retropubic prostatectomy: early outcomes from a randomized controlled phase 3 study. The Lancet 2016;388:1057-66.

20. Ludwig Boltzmann Institut für Health Technology Assessment (LBI-HTA). Roboterassistierte Chirurgie Eine systematische Übersichtsarbeit zu Wirksamkeit und Sicherheit bei ausgewählten Indikationen und anfallenden Kosten. Viena: LBI-HTA, 2015. 172 p. 